\title{
Prevalence of Helicobacter pylori in Indigenous Western Australians: comparison between urban and remote rural populations
}

\author{
Helen M Windsor, Emmanuel A Abioye-Kuteyi, Jacqueline M Leber, Susan D Morrow, Max K Bulsara and Barry J Marshall
}

$\mathrm{H}$ elicobacter pylori is a ubiquitous gastrointestinal organism which infects - more than half the population of the world. ${ }^{1}$ In First World countries, it infects $25 \%-40 \%$ of the population, with the infection generally becoming less common as standards of living rise. ${ }^{2}$ However, in developing countries, $H$. pylori infects most of the population, so that most people in Eastern Europe, Asia, Africa and South America are carriers. In Australia, about $25 \%-35 \%$ of the population is infected, ${ }^{3,4}$ with a slightly higher prevalence in males than females.

From the experience of one of us (BJM), who sees one or two symptomatic patients testing positive for $H$. pylori per week at an endoscopy clinic, H. pylori infection appears to be more common in Indigenous than non-Indigenous Australians in Perth. The clinicians at Derbarl Yerrigan Health Service (the Perth Aboriginal Medical Service) also commonly diagnose the infection serologically and treat patients both with and without performing endoscopy.

However, in the past 30 years, Australian authors have reported the absence of peptic ulcer disease in Indigenous patients, most notably in Darwin, where none of 94 patients investigated by barium meal between 1970 and 1974 were found to have a peptic ulcer. ${ }^{5}$ Similarly, a 1988 serological study of north-east Arnhem Land communities showed that less than $1 \%$ of those tested had evidence of the infection. ${ }^{6}$ In 1994, a retrospective review carried out in Alice Springs found that upper gastrointestinal endoscopies were

\section{ABSTRACT}

Objectives: To determine and compare the prevalence of Helicobacter pylori in an urban and a remote rural Western Australian Indigenous community.

Design: Cross-sectional study of Helicobacter pylori status determined by urea breath tests between mid-January 2003 and the end of June 2004.

Participants: 520 self-selected fasting participants, comprising 270 members of the Martu community at Jigalong, Punmu and Parnngurr in the East Pilbara region (129 men, 141 women; age range, 2-90 years) and 250 people from the Perth Indigenous community (96 men, 154 women; age range, $3-75$ years.

Results: The overall prevalence of $H$. pylori was $76 \%$, but the prevalence in the remote rural community was $91 \%$, compared with $60 \%$ in the urban community. The odds of having $H$. pylori were six times greater for rural than for urban participants (odds ratio $[\mathrm{OR}], 6.34 ; 95 \% \mathrm{Cl}$, 3.89-10.33). Further, the overall odds of $\mathrm{H}$. pylori infection in males (rural and urban combined) were greater than for females (OR, 1.61; 95\% Cl, 1.02-2.54). In both communities, the prevalence of infection remained relatively constant after the age of 10 .

Conclusions: The prevalence of $H$. pylori in the two Indigenous communities was two to three times higher than that in the non-Indigenous Australian population and higher than that shown in previous studies in Indigenous Australians.

MJA 2005; 182: 210-213

performed far less frequently in Indigenous patients. ${ }^{7}$ Nevertheless, $14 \%$ of Indigenous patients who underwent gastroscopy had peptic ulcers, $36 \%$ had evidence of gastritis or duodenitis, and one had a malignant ulcer. H. pylori was identified histologically in biopsies from $28 \%$ of these patients, including the one with gastric malignancy. This suggests that, when Indigenous patients are infected with $H$. pylori, they have the same range of upper gastrointestinal diseases as the non-Indigenous population. This observation correlated with a Queensland study in 2000 in which Indigenous women had about a threefold rela-

FOR EDITORIAL COMMENT, SEE PAGE 205

NHMRC Helicobacter Research Laboratory, Microbiology, University of Western Australia, Perth, WA. Helen M Windsor, PhD, Research Scientist; Susan D Morrow, BA, Research Assistant; Barry J

Marshall, FRACP, Clinical Professor, and Gastroenterologist, Sir Charles Gairdner Hospital.

Jigalong Clinic, Puntukurnu Aboriginal Medical Service, Newman, WA.

Emmanuel A Abioye-Kuteyi, MB BS, Community Medical Officer; currently, Lecturer, Obafemi

Awolowo University, Nigeria.

Department of Gastroenterology, Sir Charles Gairdner Hospital, Perth, WA.

Jacqueline M Leber, RN, Research Nurse.

School of Population Health, University of Western Australia, Perth, WA.

Max K Bulsara, MSc, Research Fellow.

Reprints will not be available from the authors. Correspondence: Professor Barry J Marshall, NHMRC

Helicobacter Research Laboratory, University of Western Australia, Crawley, Perth, WA 6009.

admin@hpylori.com.au

tive risk for gastric cancer compared with the non-Indigenous population. ${ }^{8}$

Our study was carried out to determine the prevalence of $H$. pylori infection in two Western Australian Indigenous communities, and to compare prevalences in the urban and remote rural Indigenous populations.

\section{METHODS}

The trial was conducted at two locations in Western Australia and the information and consent forms were developed in consultation with a reference group at each site. The Western Australian Indigenous Health Information and Ethics Committee approved the study based on National Health and Medical Research Council guidelines, and each participant (or his or her guardian) provided written informed consent at the time of testing. The study was carried out between mid-January 2003 and the end of June 2004.

Participants in the Perth metropolitan area were recruited at the three Derbarl Yerrigan Health service clinics and associated community centres. The participants were asked where they were born and where they had spent most of their lives - most 


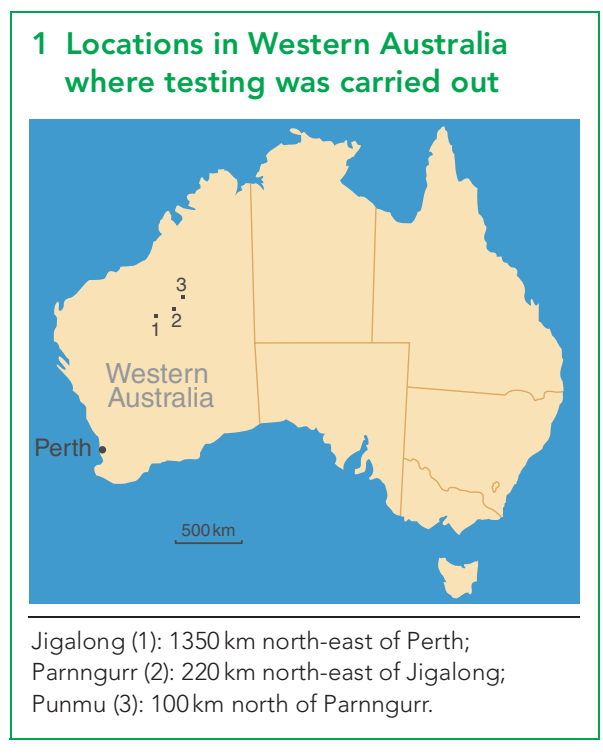

were Nyoongar people. Participants from the rural area were members of the Martu community who attended the local clinics run by the Puntukurnu Aboriginal Medical Service at Jigalong, Punmu and Parnngurr (Cotton Creek). These communities are in the remote East Pilbara region of central Western Australia (Box 1).

Participants were only included in the study if they had fasted, had not taken antibiotics in the past month and were not taking proton-pump inhibitors. All participants were given breakfast after completing the test.

The ${ }^{13} \mathrm{C}$-urea breath test (UBT) was selected for this study, as it detects active $H$. pylori infection, is simple to perform, and specimens can easily be mailed back to the testing laboratory in plastic tubes without any particular storage requirements. The ${ }^{13} \mathrm{C}$ UBT has the highest sensitivity among the non-invasive tests for the diagnosis of $H$. pylori $^{9}$ and has been well validated for use in epidemiological studies in adults as well as children. ${ }^{10,11}$ Breath tests avoid the falsepositive test results seen with serological tests, as serum often tests positive for many months after $H$. pylori infection has ceased.

Participants who had fasted were tested in the morning before having breakfast. Each received $100 \mathrm{~mL}$ of lemon-flavoured citrate drink and an initial breath sample was collected in duplicate in $10 \mathrm{~mL}$ plastic test tubes by exhalation through a plastic straw. The participant then swallowed a further $100 \mathrm{~mL}$ of lemon-flavoured drink that contained $100 \mathrm{mg}$ of ${ }^{13} \mathrm{C}$-labelled urea (Cambridge Isotope Laboratories, Andover, Mass., USA). After 30 minutes, a second breath

\begin{tabular}{|c|c|c|c|c|}
\hline \multirow[b]{2}{*}{ Age (years) } & \multicolumn{2}{|c|}{ Rural* } & \multicolumn{2}{|c|}{ Urban $^{\dagger}$} \\
\hline & Males & Females & Males & Females \\
\hline All ages & 129 & 141 & 96 & 154 \\
\hline$<10$ & 30 (11\%) & 21 (8\%) & 10 (4\%) & 12 (5\%) \\
\hline $11-20$ & $24(9 \%)$ & 37 (14\%) & 23 (9\%) & 17 (7\%) \\
\hline $21-30$ & $19(7 \%)$ & 23 (9\%) & $13(5 \%)$ & 22 (9\%) \\
\hline $31-40$ & $18(7 \%)$ & $15(6 \%)$ & $20(8 \%)$ & 33 (13\%) \\
\hline $41-50$ & $11(4 \%)$ & $15(6 \%)$ & $12(5 \%)$ & 29 (12\%) \\
\hline $51-60$ & $14(5 \%)$ & $10(4 \%)$ & $14(6 \%)$ & 19 (8\%) \\
\hline$>60$ & 13 (4\%) & 20 (7\%) & $4(2 \%)$ & 22 (9\%) \\
\hline
\end{tabular}

${ }^{*} n=270$; age range, 2-90 years. $\dagger n=250$; age range 3-75 years.

sample was collected in duplicate. The breath samples were analysed with an isotope ratio mass spectrometer (Europa Scientific, Crewe, UK) by the laboratory of the Gastroenterology Unit at the Women's and Children's Hospital in Adelaide.

Participants with a change of the ${ }^{13} \mathrm{CO}_{2}$ to ${ }^{12} \mathrm{CO}_{2}$ ratio over baseline $\left({ }^{13} \mathrm{C} \%\right.$ [per mil] $)$ of $5 \%$ or more were considered positive for H. pylori infection, while those with values of less than 5\% were considered to be negative. ${ }^{12,13}$ Tests for participants whose samples gave values for ${ }^{13} \mathrm{C} \%$ of $5.0 \pm 1.0 \%$ were repeated using the duplicate sample, and the average value was used.

\section{Statistical analysis}

Power calculations to determine how many participants were needed in three age ranges (ie, $\leqslant 30$ years, $31-50$ years, and $>50$ years) to determine the prevalence of $H$. pylori to within $\pm 10 \%$ of the true population prevalence for any age group showed that 97 participants were required in each group. Thus, with this sample size, the power of the study to detect a 50\% difference between any two of the three groups would exceed 0.8. A two-sample t-test, as well as a $\chi^{2}$ test, was used to compare demographic differences. A multivariate logistic regression model, adjusted for age and sex, was used to obtain the odds of a positive breath test. All analyses were performed with Stata 8 software. $^{14}$

\section{RESULTS}

Study participants numbered 520 (225 males and 295 females), and ranged in age from 2 to 90 years (mean age, 32.9 years). As summarised in Box 2, 270 participants were recruited in Jigalong and surrounding areas (which represented over half the population of these three communities as determined by 2001 census data), ranging in age from 2 to 90 years (mean age, 30.5 years), and 250 participants in Perth (1.2\% of the Indigenous population of Perth based on the 2001 census total of 20506 ), ranging from 3 to 75 years of age (mean age, 35.6 years). ${ }^{15}$ An additional four participants were excluded because the volume of $\mathrm{CO}_{2}$ collected in their sample tubes was too low for analysis.

In total, 395 of the 520 participants (76\%) had positive breath-test results. However, the prevalence of $H$. pylori in the remote rural communities was $91 \%$, compared with $60 \%$ in the urban population (Box 3). In both communities, the prevalence of infection remained relatively con-

3 Comparison of the age distribution of participants testing positive for $H$. pylori at each site

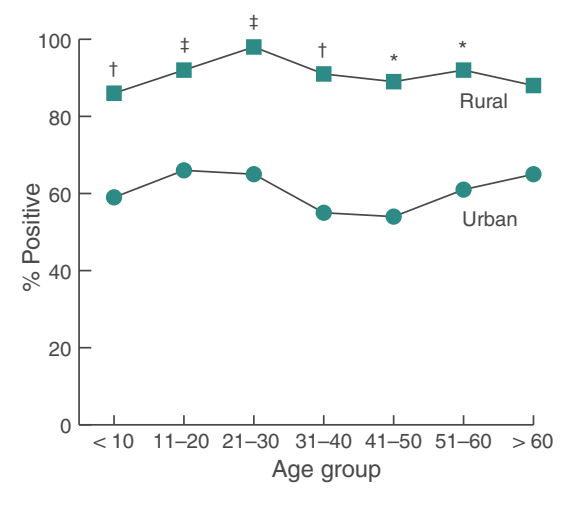

${ }^{\star} P<0.05 . \dagger P<0.01$. $¥ P<0.001$. 


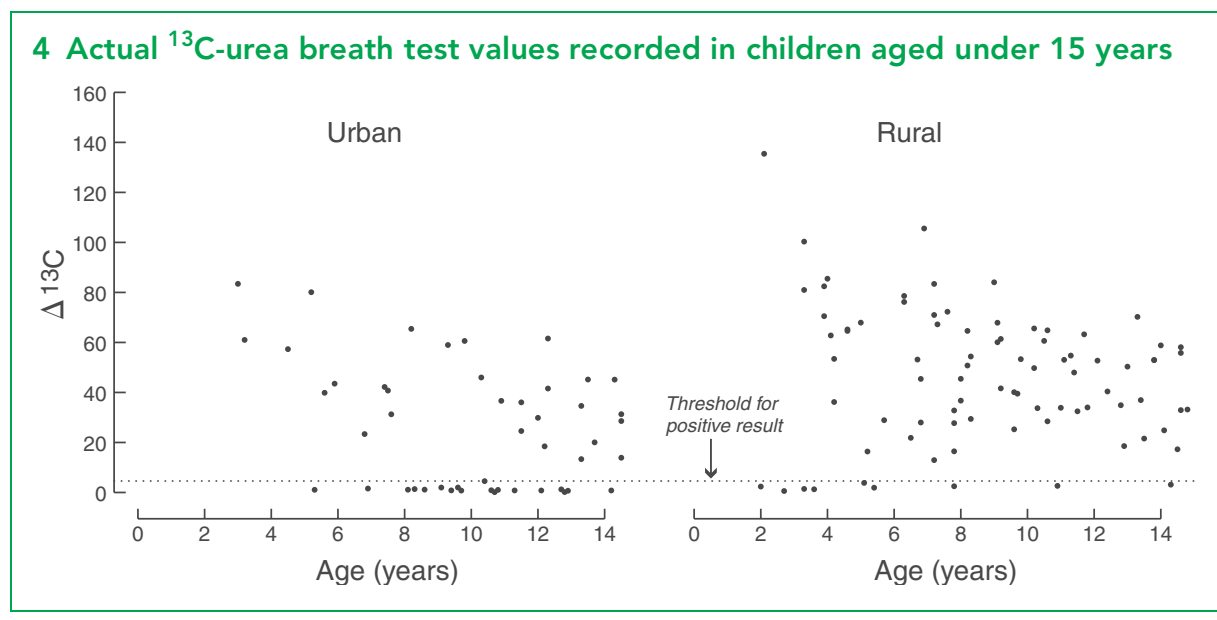

stant after the age of 10 years. The cutoff value for negative $H$. pylori status was set at $\Delta^{13} \mathrm{C} \%$ values of less than 5.0 , but most positive tests gave much higher readings (Box 4). We consider this strong evidence that these results were true-positive cases, even in small children.

The odds of being infected with $H$. pylori $\left(\Delta^{13} \mathrm{C} \%\right.$ values $\geqslant 5.0 \%$ o were six times greater for participants in the rural group than for Perth participants (odds ratio [OR], 6.34; 95\% CI, 3.89-10.33). This was adjusted for age and sex. In addition, the overall odds of $H$. pylori infection in males (rural and urban combined) were greater than for females (OR, 1.61; 95\% CI, 1.022.54; $P<0.001)$.

\section{DISCUSSION}

Our study shows that $91 \%$ of the Indigenous population in the remote rural community is infected with $H$. pylori. The bacterial infection is acquired in early childhood and, unless treated, apparently remains for life. This prevalence of $H$. pylori is equal to that reported in developing countries in South America ${ }^{16}$ and Africa, ${ }^{17}$ and is quite unlike that seen in other Australian studies. $^{4,18}$ It also refutes earlier serological data suggesting that $H$. pylori is not common in Indigenous people. ${ }^{6}$ The prevalence of $H$. pylori in the remote rural communities (91\%) contrasts with that in urban Indigenous people in the Perth region (60\%). However, a prevalence of $60 \%$ is double what would be expected in the non-Indigenous Perth population (NHMRC Helicobacter Research Laboratory, UWA; unpublished data).

In other countries, a high prevalence of $H$. pylori has correlated with contaminated drinking water ${ }^{19}$ and low socioeconomic status. $^{2,20}$ Our findings appear to parallel those seen in developing countries, but add strength to the proposition that $H$. pylori spreads from person to person by means of the faecal-oral route rather than through contaminated water. The water supply in remote communities like Jigalong is an unlikely source of infection, as it comes from a deep well under a mostly dry riverbed situated $12 \mathrm{~km}$ from the town site. The water is pumped to a closed storage tank in the town, where it is automatically chlorinated before being distributed to homes. All homes have indoor plumbing with flushing toilets, and sewage is pumped to settlement ponds about $1 \mathrm{~km}$ from the houses. Thus, under normal circumstances, the drinking water should be free of contamination. Similarly, in the Perth area, modern systems of water treatment, distribution and sewage removal are widespread.

As in studies of $H$. pylori in other countries, it appears that the bacterium is spread by person-to-person contact, typically by contamination of the home environment with faeces or vomitus. This could apply in the remote communities, where it was observed that young children sometimes do not wear nappies. Further studies are needed to try to establish the routes of infection in the community ${ }^{21}$ and within the households. $^{22}$

On average, the prevalence of $H$. pylori in urban Indigenous people in the Perth area is similar to current prevalences seen in $\mathrm{Asia}^{23}$ and the Middle East. ${ }^{24}$ However, the current $H$. pylori status of Indigenous people in Perth might represent a 40-year lag in the improvement of Indigenous health status. A similar prevalence of $H$. pylori existed in developed countries in the 1960s, when, for example, $60 \%$ of adults in California had serological evidence of infection. ${ }^{25}$ Where health status has improved, there has usu- ally been a decline in $H$. pylori prevalence among children. Thus, an improved standard of living normally results in a low prevalence of infection in 20-year-olds as against a continuing high prevalence in 50year-olds. 3,23 Paradoxically, however, this so-called "cohort effect" is not present in the Perth participants, suggesting that previous improvements in the incidence of this infectious disease have stalled.

A limitation of our study might be that the participants were self-selected and may not fully represent the communities tested. However, in Jigalong, where most of the 270 Pilbara participants live, 240 of the reported Indigenous population of 275 (based on 2001 census figures) participated in this study. In Perth, the study population was restricted by the terms of our ethical approval, which only allowed us to recruit participants associated with Derbarl Yerrigan clinics.

The strength of our study was that, unlike most other Australian surveys, we used a non-invasive test to detect $H$. pylori. This allowed participants of all ages, including young children, to be recruited, provided they could drink from a cup and blow through a straw. Serological testing would have required validation against a gold standard such as endoscopic biopsy, and this has not been done in Indigenous people. UBT is also more sensitive (94.7\% v 85\%) and specific ( $95.7 \%$ v $79 \%$ ) than serological testing. ${ }^{9}$

Our study might have been enhanced if there had been a detailed enquiry about symptoms, health status and social history from all participants. Nevertheless, Australian Bureau of Statistics data confirm that Indigenous households, despite their heterogeneity, are usually in a lower socioeconomic group. For example, the median gross weekly equivalised household income for Indigenous people in 2003 was $\$ 282$, compared with $\$ 500$ for non-Indigenous people. $^{26}$

Our findings have some important implications. Firstly, the high prevalence of $H$. pylori infection in both remote and urban Indigenous communities might translate into health risks which are possibly not being addressed. These are likely to be the same as those reported in other population groups in which growth impairment, ${ }^{27}$ iron deficiency, ${ }^{28}$ peptic ulcer ${ }^{29}$ and gastric cancer $^{25}$ have been documented.

Secondly, if medical practitioners treating Indigenous people decide to tackle the high prevalence of $H$. pylori infection, they will 
need extra resources to detect and manage this very common infectious disease. It was observed that most Indigenous patients treated for $H$. pylori infection were followed up after treatment by serological testing rather than with the UBT, which is not reimbursed under Medicare. Presently, some of the participants who tested positive for $H$. pylori have asked to be treated with antibiotics, regardless of whether or not they have symptoms. This attitude to $H$. pylori is the same as that seen worldwide, where "patient requests treatment" is one of the current recommendations from the Maastricht consensus group in Europe as a valid reason for treating the infection. ${ }^{30}$

Thirdly, if hygiene is important in preventing spread of $H$. pylori, the high prevalence of $H$. pylori in children in both communities suggests that the standard of hygiene is poor. Since the people in the remote areas have access to clean running water in their houses, the deficiency might be one of health education. An intensive health education program might be reflected in a falling incidence of $H$. pylori among children in the Pilbara. There may also be a case for yearly screening of all Indigenous children.

Lastly, there is the question of where these $H$. pylori bacteria originated. Were the Indigenous people totally free of $H$. pylori before European settlement of Australia? Further research is planned to establish the genotypes of strains of $H$. pylori from infected asymptomatic people to determine the geographical origin of the isolates. ${ }^{31}$ Indigenous people may have their own $H$. pylori strains, or they may have been first exposed to $H$. pylori by European settlers. The origin of the strains could influence clinical decisions as to whether or not to screen for H. pylori and treat infections in Indigenous people. If all the strains are found to be of the European type, H. pylori would be yet another disease introduced into Australia.

Our study exposes a need for further information on $H$. pylori infection. Proper management of infections such as these requires monitoring with available diagnostic tools. However, this will mean that health budgets need to be extended.

\section{ACKNOWLEDGEMENTS}

This work was supported by the National Health and Medical Research Council of Australia. We acknowledge the support of the reference groups for this study at both Jigalong and Derbarl Yerrigan Health Service in Perth. Thanks also to Dr Ross Butler and his team at the Women's and Children's
Hospital, Adelaide for their help throughout the study. A special thanks to Dr Raji Krishnan at Derbarl Yerrigan Maddington for her enthusiasm and interest in this research.

\section{COMPETING INTERESTS}

Barry Marshall is medical director of Tri-Med, a Perth company which distributes diagnostic tests for Helicobacter pylori.

\section{REFERENCES}

1 Parsonnet J. The incidence of Helicobacter pylori infection. Aliment Pharmacol Ther 1995; 9 Suppl 2: 45-51.

2 Malaty HM, Graham DY. Importance of childhood socioeconomic status on the current prevalence of Helicobacter pylori infection. Gut 1994; 35: 742-745.

3 Lin SK, Lambert JR, Nicholson L, et al. Prevalence of Helicobacter pylori in a representative Anglo-Celtic population of urban Melbourne. J Gastroenterol Hepatol 1998; 13: 505-510.

4 Robertson MS, Cade JF, Savoia HF, et al. Helicobacter pylori infection in the Australian community: current prevalence and lack of association with $\mathrm{ABO}$ blood groups. Intern Med J 2003; 33: 163-167.

5 Bateson EM. Duodenal ulcer - does it exist in Australian Aborigines? Aust NZ J Med 1976; 6: 545-547.

6 Dwyer B, Sun NX, Kaldor J, et al. Antibody response to Campylobacter pylori in an ethnic group lacking peptic ulceration. Scand J Infect Dis 1988; 20: 63-68.

7 Mollison LC, Lecons RJ, Thein-Htut, et al. Upper gastrointestinal endoscopy in central Australian Aborigines. Med J Aust 1994; 160: 182-184.

8 Coory M, Thompson A, Ganguly I. Cancer among people living in rural and remote Indigenous communities in Queensland. Med J Aust 2000; 173: 301-304.

9 Vaira D, Vakil N. Blood, urine, stool, breath, money, and Helicobacter pylori. Gut 2001; 48: 287-289.

10 Bazzoli F, Cecchini L, Corvaglia L, et al. Validation of the ${ }^{13} \mathrm{C}$-urea breath test for the diagnosis of Helicobacter pylori infection in children: a multicenter study. Am J Gastroentero/ 2000; 95: 646-650.

11 Bode G, Rothenbacher D, Brenner $H$, et al. Variation in the ${ }^{13} \mathrm{C}$-urea breath test value by nationality in Helicobacter pylori-infected children. Scand J Gastroenterol 1998; 33: 468-472.

12 Logan RP, Polson RJ, Misiewicz JJ, et al. Simplified single sample ${ }^{13} \mathrm{Carbon}$ urea breath test for Helicobacter pylori: comparison with histology, culture, and ELISA serology. Gut 1991; 32: 1461-1464.

13 Rowland M, Lambert I, Gormally S, et al. Carbon 13-labeled urea breath test for the diagnosis of Helicobacter pylori infection in children. $J$ Pediatr 1997; 131: 815-820.

14 Stata Statistical Software [computer program]. Version 8.0, College Station, Texas: Stata Corporation, 2003

15 Australian Bureau of Statistics. Population distribution: Aboriginal and Torres Strait Islander Australians. Census 2001. Canberra: ABS, 2002. (ABS Catalogue No. 4705.0.)
16 The Gastrointestinal Physiology Working Group. Helicobacter pylori and gastritis in Peruvian patients: relationship to socioeconomic level, age, and sex. Am J Gastroenterol 1990; 85: 819-823.

17 Sathar M, Simjee A, Wittenberg D, et al. Seroprevalence of Helicobacter pylori infection in Natal/KwaZulu, South Africa. Eur J Gastroenterol Hepatol 1994; 6: 37-41.

18 Peach HG, Pearce DC, Farish SJ. Helicobacter pylori infection in an Australian regional city: prevalence and risk factors. Med J Aust 1997; 167: 310-313.

19 Klein PD, Graham DY, Gaillour A, et al. Water source as risk factor for Helicobacter pylori infection in Peruvian children. Lancet 1991; 337: 1503-1506.

20 Staat MA, Kruszon-Moran D, McQuillan GM, et al. A population-based serologic survey of Helicobacter pylori infection in children and adolescents in the United States. J Infect Dis 1996; 174: 1120-1123.

21 Goodman KJ, Correa P, Tengana Aux HJ, et al. Helicobacter pylori infection in the Colombian Andes: a population-based study of transmission pathways. Am J Epidemiol 1996; 144: 290299.

22 Gibson JR, Slater E, Xerry J, et al. Use of an amplified-fragment length polymorphism technique to fingerprint and differentiate isolates of Helicobacter pylori. J Clin Microbiol 1998; 36: 2580-2585.

23 Mitchell HM, Li YY, Hu PJ, et al. Epidemiology of Helicobacter pylori in southern China: identification of early childhood as the critical period for acquisition. J Infect Dis 1992; 166: 149-153.

24 Niv Y, Abuksis G, Koren R. ${ }^{13} \mathrm{C}$-urea breath test, referral patterns, and results in children. J Clin Gastroenterol 2003; 37: 142-146.

25 Parsonnet J, Friedman GD, Vandersteen DP, et al. Helicobacter pylori infection and the risk of gastric carcinoma. N Engl J Med 1991; 325: 1127-1131.

26 Steering Committee for the Review of Government Service Provision. Overcoming Indigenous disadvantage: key indicators 2003. Available at: www.pc.gov.au/gsp/reports/indigenous/keyindicators $2003 /$ keyindicators2003.pdf (accessed Jul 2004).

27 Passaro DJ, Taylor DN, Gilman RH, et al. Growth slowing after acute Helicobacter pylori infection is age-dependent. J Pediatr Gastroenterol Nutr 2002; 35: 522-526.

28 Peach HG, Bath NE, Farish SJ. Helicobacter pylori infection: an added stressor on iron status of women in the community. Med $\mathrm{J}$ Aust 1998; 169: 188-190.

29 Mitani K, Tatsuta M, lishi H, et al. Helicobacter pylori infection as a risk factor for gastric ulceration. Hepatogastroenterology 2004; 51: 309312.

30 Malfertheiner $\mathrm{P}$, Megraud F, O'Morain C, et al. Current concepts in the management of Helicobacter pylori infection - the Maastricht 22000 consensus report. Aliment Pharmacol Ther 2002; 16: 167-180.

31 van Doorn LJ, Figueiredo C, Megraud F, et al. Geographic distribution of vacA allelic types of Helicobacter pylori. Gastroenterology 1999; 116: 823-830.

(Received 9 Sep 2004, accepted 14 Dec 2004) 